\title{
Clinical features as potential prognostic factors in patients treated with nivolumab for highly pretreated metastatic gastric cancer: a multicenter retrospective study
}

Akihiko Sano ${ }^{1}$ [D, Makoto Sohda ${ }^{*}$, Nobuhiro Nakazawa ${ }^{1}$, Yasunari Ubukata ${ }^{1}$, Kengo Kuriyama', Akiharu Kimura', Norimichi Kogure ${ }^{1}$, Hisashi Hosaka², Atsushi Naganuma ${ }^{3}$, Masanori Sekiguchi ${ }^{4}$, Kana Saito ${ }^{5}$, Kyoichi Ogata ${ }^{1}$, Makoto Sakai ${ }^{1}$, Hiroomi Ogawa ${ }^{1}$, Ken Shirabe ${ }^{1}$ and Hiroshi Saeki ${ }^{1}$

\begin{abstract}
Background: Although nivolumab (anti-programmed cell death-1 antibody) is a promising approach for advanced gastric cancer (AGC), the response rate remains limited. The aim of this multicenter retrospective study was to determine if clinical features could serve as prognostic factors of the efficacy of nivolumab in patients with AGC.

Methods: Fifty-eight patients with AGC who were treated with nivolumab as a third or later line from October 2017 to December 2018 at any of five clinical sites were enrolled in the study. The correlation between the best overall response and clinical features was investigated. Overall survival and progression-free survival after initiation of nivolumab were calculated and clinical features that could be predictors of the prognosis were sought.

Results: The disease control rate (DCR) for nivolumab was $36.2 \%$ and was significantly correlated with performance status $(p=0.021)$, metastasis to one organ $(p=0.006)$, and grade 2 or higher immune-related adverse events $(p=0.027)$. There was also a significant association between response to nivolumab and ability to receive subsequent chemotherapy $(p=0.022)$. In the analysis of overall survival, the following variables were identified as being significantly associated with a poor outcome: Eastern Cooperative Oncology Group performance status $\geq 1$, prior treatment with trastuzumab, no immune-related adverse events, lack of a response to nivolumab, and inability to receive subsequent chemotherapy.
\end{abstract}

Conclusion: The findings of this study suggest that nivolumab may be ineffective for AGC in patients with poor performance status and those with a history of treatment with trastuzumab.

Keywords: Nivolumab, Advanced gastric cancer, Performance status, Trastuzumab, Immune-related adverse events

*Correspondence: msohda@gunma-u.ac.jp

1 Department of General Surgical Science, Gunma University Graduate School of Medicine, 3-39-22 Showa-machi, Maebashi, Gunma 371-8511, Japan

Full list of author information is available at the end of the article

\begin{abstract}
Background
Despite the recent advent of various anticancer drugs, there is still no cure for unresectable advanced or recurrent gastric cancer (AGC). According to the Japanese gastric cancer treatment guidelines [1], oral fluoropyrimidine plus platinum is the standard first-line chemotherapy for human epidermal growth factor receptor 2 (HER2)-negative unresectable AGC [2-6]. In contrast,
\end{abstract}

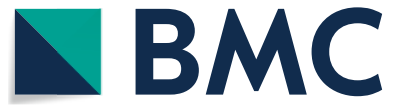

(c) The Author(s) 2021. Open Access This article is licensed under a Creative Commons Attribution 4.0 International License, which permits use, sharing, adaptation, distribution and reproduction in any medium or format, as long as you give appropriate credit to the original author(s) and the source, provide a link to the Creative Commons licence, and indicate if changes were made. The images or other third party material in this article are included in the article's Creative Commons licence, unless indicated otherwise in a credit line to the material. If material is not included in the article's Creative Commons licence and your intended use is not permitted by statutory regulation or exceeds the permitted use, you will need to obtain permission directly from the copyright holder. To view a copy of this licence, visit http://creativecommons.org/licenses/by/4.0/. The Creative Commons Public Domain Dedication waiver (http://creativeco $\mathrm{mmons}$.org/publicdomain/zero/1.0/) applies to the data made available in this article, unless otherwise stated in a credit line to the data. 
trastuzumab is recommended in combination with firstline chemotherapy in patients with HER-2-positive AGC based on the results of the ToGA trial [7]. For second-line chemotherapy, paclitaxel plus ramucirumab, an anti-vascular endothelial growth factor receptor 2 antibody, was shown to be superior to weekly paclitaxel monotherapy in a RAINBOW trial [8]. In a large Phase III ATTRAC TION-2 study, nivolumab, a monoclonal antibody targeting programmed cell death-1 (PD-1), was shown to have significant survival benefits compared with placebo in patients with advanced gastric or esophagogastric junction cancer [9]. After the results of this study were published, nivolumab monotherapy was recommended as a third-line treatment for patients with unresectable advanced or recurrent gastric/esophagogastric junctional cancer in Japan. Furthermore, the long-term efficacy of nivolumab monotherapy was confirmed at the 3-year follow-up [10]. In this study, median overall survival (OS) was significantly longer in the nivolumab monotherapy group than in the placebo group (5.3 months vs 4.1 months; 3 -year survival rate, $5.6 \%$ vs $1.9 \%$; hazard ratio $(\mathrm{HR})=0.62, p<0.0001)$. And a survival benefit of treatment beyond progression with nivolumab was suggested. Although this anti-PD-1 monoclonal antibody is a promising approach for patients with advanced gastric cancer, the response rate is still limited. There is a need to identify novel biomarkers that could help identify patients who would benefit from nivolumab and those with primary resistance.

In this multicenter retrospective study, we analyzed the clinical features of patients with unresectable AGC who received nivolumab to identify if any of these features could serve as potential prognostic markers.

\section{Methods}

\section{Patients and data collection}

Patients with AGC that was histologically confirmed to be adenocarcinoma who were treated with nivolumab monotherapy as third-line or later line between October 2017 and December 2018 at Gunma University Hospital, Gunma Prefectural Cancer Center, National Hospital Organization Takasaki General Medical Center, Isesaki Municipal Hospital, or Japan Community Healthcare Organization Gunma Central Hospital were retrospectively reviewed. Patients who had previously received immunotherapy were excluded. The following clinical data on patient characteristics were retrospectively collected from the medical records: age, sex, Eastern Cooperative Oncology Group performance status (ECOG PS), disease status (metastatic or relapsed), primary site, histological type (Lauren classification), HER-2 status, site of metastasis, organs with metastasis, previous treatment regimens, and therapies before initiating treatment with nivolumab.

\section{Treatment and assessment}

Nivolumab was administered intravenously at a dose of $3 \mathrm{mg} / \mathrm{kg}$ or $240 \mathrm{mg}$ flat dose every 2 weeks until disease progression, clinical deterioration, unacceptable toxicity occurred, or the patient refused to continue treatment. The best overall response was evaluated and classified as complete remission (CR), partial response (PR), stable disease (SD), or progressive disease (PD) according to the Response Evaluation Criteria in Solid Tumors (RECIST) guidelines version 1.1 [11] using computed tomography at 6-8-week intervals during nivolumab therapy. Patients with a SD, PR, or CR were considered to be "responders" and those with PD were assumed to be "non-responders". With regard to the safety analysis, adverse events (AEs) linked to use of nivolumab were evaluated according to the National Cancer Institute Common Terminology Criteria for Adverse Events version 5.0 and included immune-related AEs (irAEs). In previous studies [1214], irAEs were defined as AEs with a potential immune cause, events for which frequent monitoring was needed, or for which immunosuppressive and/or endocrine therapy was prescribed according to severity. OS and progression-free survival (PFS) were assessed from the date of initiation of treatment with nivolumab. OS was measured until death or censored at the latest follow-up for surviving patients. PFS was measured until progression or death from any cause and censored at the date when the patient was last confirmed to be progression-free.

\section{Statistical analysis}

Differences between two groups were compared using Fisher's exact test for categorical variables and the MannWhitney $U$ test for quantitative variables. Survival curves were constructed using the Kaplan-Meier method and compared using the log-rank test. The Cox proportional hazards regression model was used to calculate HRs with 95\% confidence intervals (CIs). All data were analyzed using EZR, which is a freely available easy-to-use medical statistical software package [15]. A $p$-value $<0.05$ was considered statistically significant.

\section{Results \\ Clinical characteristics of patients with AGC treated by nivolumab}

The study population consisted of 58 patients who were treated with nivolumab for AGC. Clinical characteristics of patients in this study were listed in Table 1 . The 58 patients included 45 men (78\%) and 13 women (22\%). The median age at the time of initiation of nivolumab was 66 years (range, 38-82). Eight patients (14\%) had 
Table 1 Characteristics of patients before treatment of nivolumab

\begin{tabular}{|c|c|}
\hline Variables & $\begin{array}{l}n=58 \\
\text { No. }(\%)\end{array}$ \\
\hline \multicolumn{2}{|l|}{ Sex } \\
\hline Male & $45(78 \%)$ \\
\hline Female & $13(22 \%)$ \\
\hline Age (years) (Median, Range) & $66(38-82)$ \\
\hline \multicolumn{2}{|l|}{ ECOG performance status } \\
\hline 0 & $8(14 \%)$ \\
\hline 1 & $36(62 \%)$ \\
\hline 2 & $12(21 \%)$ \\
\hline 3 & $2(3 \%)$ \\
\hline \multicolumn{2}{|l|}{ Disease status } \\
\hline Metastatic & $43(74 \%)$ \\
\hline Relapsed & $15(26 \%)$ \\
\hline \multicolumn{2}{|l|}{ Primary site } \\
\hline Gastric & $49(84 \%)$ \\
\hline Esophagogastric junction & $9(16 \%)$ \\
\hline \multicolumn{2}{|l|}{ Histological type } \\
\hline Intestinal type & $34(59 \%)$ \\
\hline Diffuse type & $24(41 \%)$ \\
\hline \multicolumn{2}{|l|}{ HER-2 status } \\
\hline Positive & $13(22 \%)$ \\
\hline \multicolumn{2}{|l|}{ Site of metastases } \\
\hline Lymph nodes & $41(72 \%)$ \\
\hline Peritoneum & $27(47 \%)$ \\
\hline Liver & $20(34 \%)$ \\
\hline Lung & $12(21 \%)$ \\
\hline Bone & $9(16 \%)$ \\
\hline Other & $7(12 \%)$ \\
\hline \multicolumn{2}{|l|}{ Organs with metastasis } \\
\hline 1 & $17(29 \%)$ \\
\hline 2 & $24(42 \%)$ \\
\hline 3 & $13(22 \%)$ \\
\hline$\geq 4$ & $4(7 \%)$ \\
\hline \multicolumn{2}{|l|}{ Previous treatment regimens } \\
\hline 2 & $35(60 \%)$ \\
\hline 3 & $18(31 \%)$ \\
\hline$\geq 4$ & $5(9 \%)$ \\
\hline \multicolumn{2}{|l|}{ Previous therapies } \\
\hline Pyrimidine analogs & $56(97 \%)$ \\
\hline Platinum & $50(86 \%)$ \\
\hline Taxane & $55(95 \%)$ \\
\hline Ramucirumab & $48(83 \%)$ \\
\hline Trastuzumab & $11(19 \%)$ \\
\hline Irinotecan & $16(28 \%)$ \\
\hline Treatment period before nivolumab (months) & $14.9(4.9-64.6)$ \\
\hline \multicolumn{2}{|l|}{ Immune-related adverse events } \\
\hline Positive & $10(17 \%)$ \\
\hline
\end{tabular}

Table 2 Best overall responses to nivolumab $(n=58)$

\begin{tabular}{ll}
\hline Best overall response & $\mathbf{n}(\%)$ \\
\hline Complete remission (CR) & 0 \\
Partial response (PR) & $4(7 \%)$ \\
Stable disease (SD) & $17(29 \%)$ \\
Progressive disease (PD) & $37(64 \%)$ \\
Objective response rate (ORR, CR+PR) & $4(7 \%)$ \\
Disease control rate (DCR, ORR + SD) & $21(36 \%)$ \\
\hline
\end{tabular}

an ECOG PS of 0 and 50 (86\%) had an ECOG PS of $\geq 1$. At diagnosis, 43 patients (74\%) were classified as metastatic and $15(26 \%)$ as relapsed. Forty-nine patients (84\%) had gastric cancer and nine (16\%) had esophagogastric junction cancer. Thirty-four patients (59\%) had intestinal type and 13 (22\%) had HER-2 positive disease. Seventeen patients $(29 \%)$ had metastasis to one organ, and 41 (71\%) had metastasis to two or more organs. Fifty-six patients $(97 \%)$ received regimens containing pyrimidine analogs, 50 (86\%) received platinum-containing regimens, 55 (95\%) received a taxane, and 48 (83\%) received regimens containing ramucirumab. In 58 patients treated with nivolumab, none of the patients achieved a CR. Four patients achieved a PR (7\%), 17 achieved SD (29\%), and the remaining 37 had PD (64\%), resulting in an objective response rate of $7 \%$ and a disease control rate (DCR) of 36\% (Table 2). In this study population, no obvious Pseudo-progression or hyper-progression was observed. Table 3 summarizes the clinical characteristics for patients treated with nivolumab in responder and non-responder groups. Most of the clinical characteristics were similarly distributed between the patients who responded to nivolumab and those who did not. However, the DCR was significantly correlated with ECOG PS of $0(p=0.021)$ and with metastasis to one organ $(p=0.006)$.

\section{Safety of nivolumab monotherapy}

Treatment-related adverse events (TRAEs) are summarized in Table 4. Thirty-one patients (53\%) experienced TRAEs; these were grade 2 or higher in 18 patients $(31 \%)$. The most common TRAEs were anorexia $(n=9)$, malaise $(n=6)$, and nausea $(n=3)$. Grade 2 or higher TRAEs were observed in 10 patients (17\%), with anorexia in $3(5 \%)$, and upper gastrointestinal hemorrhage in 2 (3\%). Ten patients (17\%) experienced grade 2 or higher immune-related adverse events (irAEs); liver enzyme elevation $(n=3)$, and peripheral sensory neuropathy and hypothyroidism occurred in 2 patients each. The DCR was significantly higher in patients with grade 2 or higher irAEs $(p=0.027$; Table 3$)$. 
Table 3 Characteristics of patients treated with nivolumab in responder and non-responder groups

\begin{tabular}{|c|c|c|c|}
\hline Variables & $\begin{array}{l}\text { Responder }(n=21) \\
\text { No. }(\%)\end{array}$ & $\begin{array}{l}\text { Non-responder }(n=37) \\
\text { No. }(\%)\end{array}$ & $p$ \\
\hline \multicolumn{4}{|l|}{ Sex } \\
\hline Male & 18 (86\%) & $27(73 \%)$ & \multirow[t]{2}{*}{0.338} \\
\hline Female & $3(14 \%)$ & $10(27 \%)$ & \\
\hline Age (years) (Median, Range) & $66(53-76)$ & $66(38-82)$ & 0.581 \\
\hline \multicolumn{4}{|l|}{ ECOG performance status } \\
\hline 0 & $6(29 \%)$ & $2(5 \%)$ & \multirow[t]{2}{*}{0.021} \\
\hline$\geq 1$ & $15(71 \%)$ & 35 (95\%) & \\
\hline \multicolumn{4}{|l|}{ Disease status } \\
\hline Metastatic & $16(76 \%)$ & $27(73 \%)$ & \multirow[t]{2}{*}{1} \\
\hline Relapsed & $5(24 \%)$ & $10(27 \%)$ & \\
\hline \multicolumn{4}{|l|}{ Primary site } \\
\hline Gastric & $17(81 \%)$ & $32(87 \%)$ & \multirow[t]{2}{*}{0.71} \\
\hline Esophagogastric junction & $4(19 \%)$ & $5(14 \%)$ & \\
\hline \multicolumn{4}{|l|}{ Histological type } \\
\hline Intestinal type & $12(57 \%)$ & $22(60 \%)$ & \multirow[t]{2}{*}{1} \\
\hline Diffuse type & $9(43 \%)$ & $15(40 \%)$ & \\
\hline \multicolumn{4}{|l|}{ HER-2 status } \\
\hline Positive & $2(10 \%)$ & $11(30 \%)$ & 0.106 \\
\hline \multicolumn{4}{|l|}{ Site of metastases } \\
\hline Lymph nodes & $13(62 \%)$ & $28(76 \%)$ & 0.369 \\
\hline Hematogenous & $9(43 \%)$ & $24(65 \%)$ & 0.167 \\
\hline Peritoneum & $12(57 \%)$ & 15 (41\%) & 0.278 \\
\hline \multicolumn{4}{|l|}{ Organs with metastasis } \\
\hline 1 & $11(52 \%)$ & $6(16 \%)$ & \multirow[t]{2}{*}{0.006} \\
\hline$\geq 2$ & $10(48 \%)$ & $31(84 \%)$ & \\
\hline \multicolumn{4}{|l|}{ Previous treatment regimens } \\
\hline 2 & $14(67 \%)$ & $21(57 \%)$ & \multirow[t]{3}{*}{0.704} \\
\hline 3 & $5(24 \%)$ & $13(35 \%)$ & \\
\hline$\geq 4$ & $2(9 \%)$ & $3(8 \%)$ & \\
\hline \multicolumn{4}{|l|}{ Previous therapies } \\
\hline Pyrimidine analogs & $20(95 \%)$ & $36(97 \%)$ & 1 \\
\hline Platinum & 18 (86\%) & $32(87 \%)$ & 1 \\
\hline Taxane & $20(95 \%)$ & $35(95 \%)$ & 1 \\
\hline Ramucirumab & $16(76 \%)$ & $32(87 \%)$ & 0.471 \\
\hline Trastuzumab & $2(10 \%)$ & $9(24 \%)$ & 0.296 \\
\hline Irinotecan & $5(24 \%)$ & $11(30 \%)$ & 0.764 \\
\hline Treatment period before nivolumab (months) & $17.3(8.1-37.1)$ & $14.6(4.9-64.6)$ & 0.225 \\
\hline \multicolumn{4}{|l|}{ Immune-related adverse events } \\
\hline Positive & $7(33 \%)$ & $3(8 \%)$ & 0.027 \\
\hline
\end{tabular}

\section{Survival in responders and non-responders}

The Kaplan-Meier curves for OS and PFS are shown in Fig. 1. The median OS was 5.95 months (95\% CI 4.27.7) and median PFS was 1.6 months (95\% CI 1.4-2.6); Fig. 1A, C). Both OS and PFS were significantly longer in responders than in non-responders (Fig. 1B, D). Median OS was not reached (95\% CI 8.0-NA) in responders and was 3.8 months (95\% CI 2.3-5.1) in non-responders $(p<0.0001)$.

\section{Association of nivolumab response with subsequent chemotherapy}

The association between response to nivolumab and subsequent chemotherapy after nivolumab is shown in 
Table 4 Treatment-related adverse events (TRAEs)

\begin{tabular}{lll}
\hline Treatment-related adverse events & $\mathbf{n}(\%)$ & \\
\cline { 2 - 3 } & Any grade & $\geq$ grade $\mathbf{2}$ \\
\hline All TRAEs & $31(53 \%)$ & $18(31 \%)$ \\
Common TRAEs & $25(43 \%)$ & $10(17 \%)$ \\
Anorexia & $9(16 \%)$ & $3(5 \%)$ \\
Malaise & $6(10 \%)$ & 0 \\
Nausea & $3(5 \%)$ & 0 \\
Upper gastrointestinal hemorrhage & $2(3 \%)$ & $2(3 \%)$ \\
Fever & $2(3 \%)$ & 0 \\
Localized edema & $2(3 \%)$ & 0 \\
Creatinine increased & $2(3 \%)$ & 0 \\
Dysgeusia & $2(3 \%)$ & 0 \\
Pruritus & $2(3 \%)$ & 0 \\
Nail change & $2(3 \%)$ & 0 \\
Anemia & $1(2 \%)$ & $1(2 \%)$ \\
Palpitations & $1(2 \%)$ & $1(2 \%)$ \\
Colonic perforation & $1(2 \%)$ & $1(2 \%)$ \\
Neutrophil count decreased & $1(2 \%)$ & $1(2 \%)$ \\
Dyspnea & $1(2 \%)$ & $1(2 \%)$ \\
Pleural effusion & $1(2 \%)$ & $1(2 \%)$ \\
Eosinophilia & $1(2 \%)$ & 0 \\
Constipation & $1(2 \%)$ & 0 \\
Platelet count decreased & $1(2 \%)$ & 0 \\
Proteinuria & $1(2 \%)$ & 0 \\
Cough & $1(2 \%)$ & 0 \\
Immune-related adverse events (irAEs) & $20(35 \%)$ & $10(17 \%)$ \\
Liver enzyme elevation & $7(12 \%)$ & $3(5 \%)$ \\
Peripheral sensory neuropathy & $4(7 \%)$ & $2(3 \%)$ \\
Rash maculopapular & $4(7 \%)$ & $1(2 \%)$ \\
Colitis & $4(7 \%)$ & 0 \\
Hypothyroidism & $2(3 \%)$ & $2(3 \%)$ \\
Hyperglycemia & $1(2 \%)$ & $1(2 \%)$ \\
Esophagitis & $1(2 \%)$ & $1(2 \%)$ \\
Hypopituitarism & & $1(2 \%)$ \\
\hline
\end{tabular}

Table 5. At the time of analysis, three of the 58 patients were continuing to receive nivolumab. Chemotherapy was able to be started in $24(44 \%)$ of 55 patients who were finally judged to have PD but not in 31 (56\%). The nivolumab responder group had a significantly higher rate of subsequent chemotherapy than the nonresponder group $(p=0.022)$. Fifteen patients $(62 \%)$ received irinotecan subsequent to nivolumab, 9 (38\%) received a taxane, 7 (29\%) received a pyrimidine analog, $6(25 \%)$ received platinum, $6(25 \%)$ received ramucirumab, and $2(8 \%)$ received trifluridine/tipiracil. The characteristics of the 55 patients in whom subsequent chemotherapy was or was not possible are shown in Table 6 . The ability to receive subsequent chemotherapy was significantly correlated with ECOG PS at the start of nivolumab therapy $(p<0.001)$ and whether or not there was a prior trastuzumab use $(p=0.015)$. There was a significant correlation between responsiveness to nivolumab and being able to undergo chemotherapy subsequent to this agent $(p=0.022)$. Figure 2 shows the Kaplan-Meier curves for OS in patients in whom subsequent chemotherapy was possible and those in whom it was not. Median OS was 9.7 months (95\% CI 6.3-17.8) in the group that subsequently received chemotherapy and 2.9 months (95\% CI 1.9-4.4) in the group that did not $(p<0.0001)$.

\section{Association of clinical features with OS and PFS}

Table 7 shows OS and PFS in patients treated with nivolumab. In the Cox proportional hazards regression model, the following variables were identified as being significantly associated with a poor outcome: ECOG PS $\geq 1 \quad(p=0.018)$, prior treatment with trastuzumab $(p=0.040)$, no irAEs $(p=0.017)$, no response to nivolumab $(p<0.001)$, and inability to receive subsequent chemotherapy $(p<0.001)$. Other than non-responsiveness to nivolumab, no variables were significantly associated with PFS.

\section{Discussion}

This multicenter retrospective study reports the results of nivolumab monotherapy in patients treated according to the ATTRACTION-2 trial schedule [9] for metastatic and relapsed gastric or esophagogastric junction cancer who were refractory to or intolerant of at least two previous chemotherapy regimens. In this study, the objective response rate was $7 \%$ and the DCR was $36 \%$. Median OS was 5.95 months and PFS was 1.6 months. OS and PFS were significantly better in the group that responded to nivolumab. Prognostic factors that predicted poor OS after initiation of nivolumab monotherapy included an ECOG PS $\geq 1$, history of treatment with trastuzumab, no irAEs, lack of response to nivolumab, and inability to receive subsequent chemotherapy.

In the ATTRACTION-2 trial $[9,10]$, patients who received nivolumab had a median OS of 5.3 months $(95 \%$ CI 4.60-6.37) and a 12-month OS rate of $26.2 \%(95 \%$ CI 20.7-32.0). Median OS after nivolumab monotherapy for advanced or recurrent gastric/esophagogastric junctional cancer in patients who had received two or more chemotherapy regimens was reported to be $4.3-7.6$ months in several retrospective studies [16-20], which is similar to the median OS time of 5.95 months in this study. The ATTRACTION-2 trial demonstrated the efficacy of nivolumab in Asian patients with pretreated AGC. Similarly in Western patients with AGC, nivolumab has been shown to be feasible and effective [20]. However, 


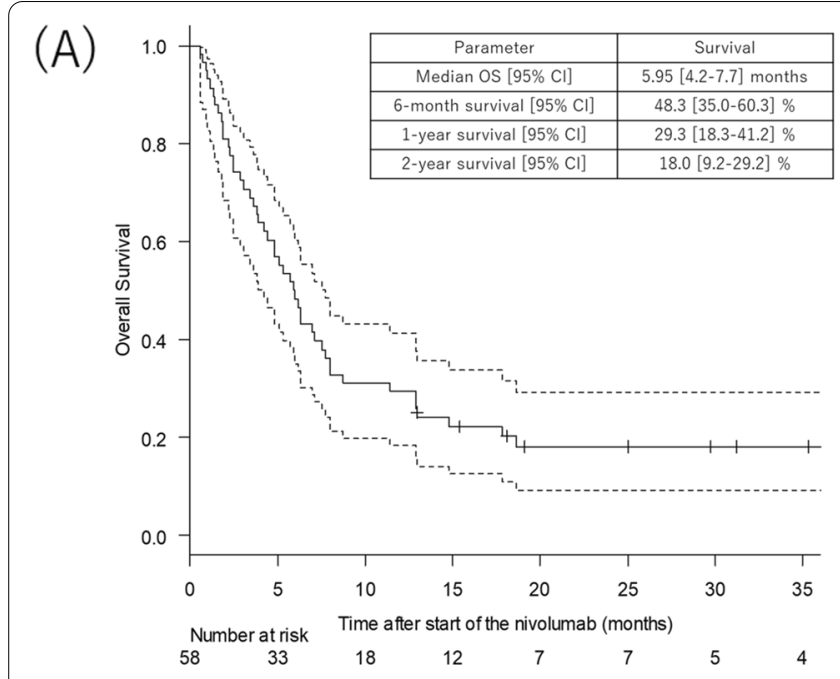

(B)

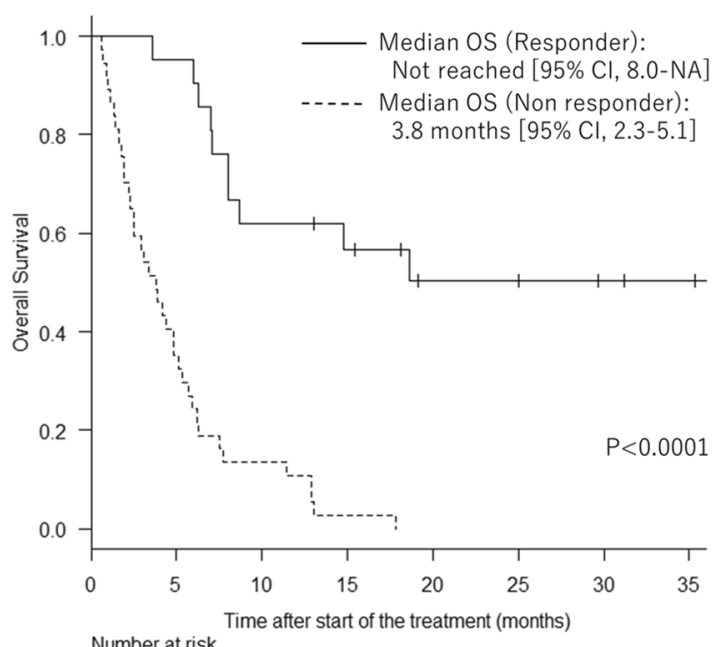

(C)

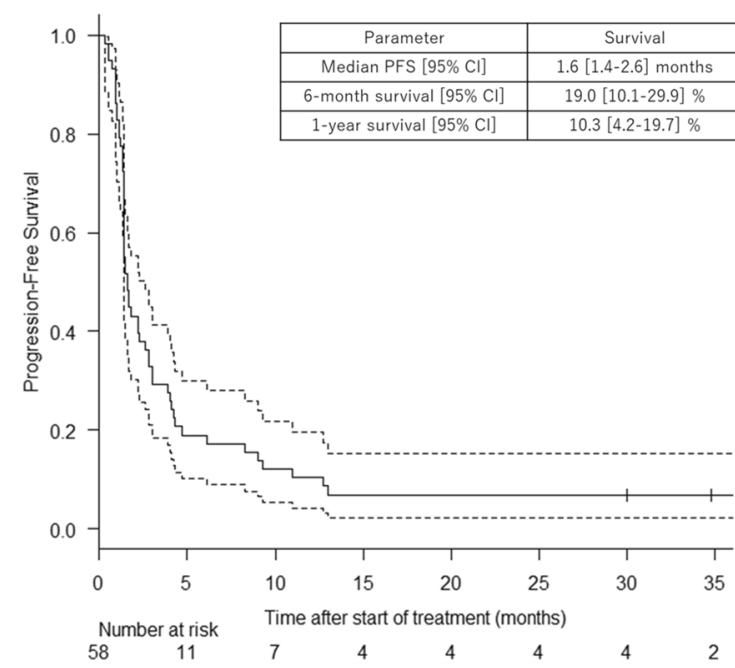

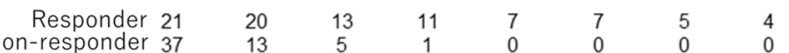

(D)

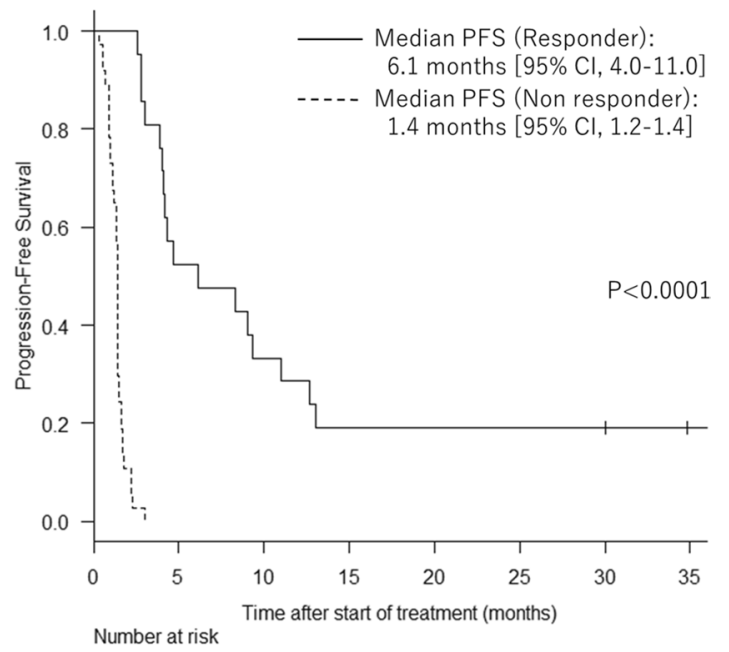

$\begin{array}{rccccccc}\text { Responder } & 11 & 7 & 4 & 4 & 4 & 4 & 2\end{array}$

Fig. 1 Overall (A, B) and progression-free (C, D) Kaplan-Meier survival curves for patients treated with nivolumab. After start of the nivolumab therapy, median overall survival (A) was 5.95 months and median progression-free survival $(\mathbf{C})$ was 1.6 months. Patients who responded to nivolumab had significantly better overall survival (B) and progression-free survival (D) $(p<0.0001)$

Table 5 Subsequent chemotherapy after nivolumab $(n=55)$

\begin{tabular}{|c|c|c|c|c|}
\hline Subsequent chemotherapy & All patients $(n=55)$ & Responder $(n=18)$ & Non-responder $(n=37)$ & $p$ \\
\hline No & $31(56 \%)$ & $6(33 \%)$ & $25(68 \%)$ & 0.022 \\
\hline Yes & $24(44 \%)$ & $12(67 \%)$ & $12(32 \%)$ & \\
\hline Treatment after nivolumab & All patients $(n=24)$ & Responder $(n=12)$ & Non-responder $(n=12)$ & $p$ \\
\hline Irinotecan & $15(62 \%)$ & $6(50 \%)$ & $9(75 \%)$ & 0.226 \\
\hline Taxane & $9(38 \%)$ & $6(50 \%)$ & $3(25 \%)$ & 0.411 \\
\hline Pyrimidine analog & $7(29 \%)$ & $3(25 \%)$ & $4(33 \%)$ & 0.673 \\
\hline Platinum & $6(25 \%)$ & $3(25 \%)$ & $3(25 \%)$ & 1 \\
\hline Ramucirumab & $6(25 \%)$ & $4(33 \%)$ & $2(17 \%)$ & 0.645 \\
\hline Trifluridine/tipiracil & $2(8 \%)$ & $2(17 \%)$ & $0(0 \%)$ & 0.411 \\
\hline
\end{tabular}


Table 6 Characteristics of patients with or without subsequent chemotherapy after treatment of nivolumab

\begin{tabular}{|c|c|c|c|c|}
\hline \multirow[t]{2}{*}{ Variables } & \multirow{2}{*}{$\begin{array}{l}\text { All patients }(n=55) \\
\text { No. }(\%)\end{array}$} & \multicolumn{2}{|c|}{ Subsequent chemotherapy } & \multirow[t]{2}{*}{$p$} \\
\hline & & Yes $(n=24)$ & No $(n=31)$ & \\
\hline \multicolumn{5}{|l|}{ Sex } \\
\hline Male & $42(76 \%)$ & $18(75 \%)$ & $24(77 \%)$ & \multirow[t]{2}{*}{1} \\
\hline Female & $13(23 \%)$ & $6(25 \%)$ & $7(23 \%)$ & \\
\hline Age (years) (Median, Range) & $66(38-82)$ & $66(38-82)$ & $68(49-80)$ & 0.48 \\
\hline \multicolumn{5}{|l|}{ ECOG performance status } \\
\hline 0 & $8(14 \%)$ & $8(33 \%)$ & $0(0 \%)$ & \multirow[t]{2}{*}{$<0.001$} \\
\hline$\geq 1$ & $47(86 \%)$ & $16(67 \%)$ & $31(100 \%)$ & \\
\hline \multicolumn{5}{|l|}{ Disease status } \\
\hline Metastatic & $41(74 \%)$ & $18(75 \%)$ & $23(74 \%)$ & \multirow[t]{2}{*}{1} \\
\hline Relapsed & $14(26 \%)$ & $6(25 \%)$ & $8(26 \%)$ & \\
\hline \multicolumn{5}{|l|}{ Primary site } \\
\hline Gastric & $48(87 \%)$ & $22(92 \%)$ & $26(84 \%)$ & \multirow[t]{2}{*}{0.451} \\
\hline Esophagogastric junction & $7(13 \%)$ & $2(8 \%)$ & $5(16 \%)$ & \\
\hline \multicolumn{5}{|l|}{ Histological type } \\
\hline Intestinal type & $31(56 \%)$ & $12(50 \%)$ & 19 (61\%) & \multirow[t]{2}{*}{0.426} \\
\hline Diffuse type & $24(44 \%)$ & $12(50 \%)$ & $12(39 \%)$ & \\
\hline \multicolumn{5}{|l|}{ HER-2 status } \\
\hline Positive & $13(24 \%)$ & $3(12 \%)$ & $10(32 \%)$ & 0.116 \\
\hline \multicolumn{5}{|l|}{ Site of metastases } \\
\hline Lymph nodes & $38(69 \%)$ & $15(62 \%)$ & $23(74 \%)$ & 0.391 \\
\hline Hematogenous & $32(58 \%)$ & $11(46 \%)$ & $21(68 \%)$ & 0.168 \\
\hline Peritoneum & $26(47 \%)$ & $12(50 \%)$ & $14(45 \%)$ & 0.789 \\
\hline \multicolumn{5}{|l|}{ Organs with metastasis } \\
\hline 1 & $16(29 \%)$ & $10(42 \%)$ & $6(19 \%)$ & \multirow[t]{2}{*}{0.083} \\
\hline$\geq 2$ & $39(71 \%)$ & $14(58 \%)$ & $25(81 \%)$ & \\
\hline \multicolumn{5}{|l|}{ Previous treatment regimens } \\
\hline 2 & $34(62 \%)$ & $17(71 \%)$ & $17(55 \%)$ & \multirow[t]{3}{*}{0.459} \\
\hline 3 & $16(29)$ & $5(21 \%)$ & $11(35 \%)$ & \\
\hline$\geq 4$ & $5(9 \%)$ & $2(8 \%)$ & $3(10 \%)$ & \\
\hline \multicolumn{5}{|l|}{ Previous therapies } \\
\hline Pyrimidine analogs & $53(96 \%)$ & $23(96 \%)$ & 30 (97\%) & 1 \\
\hline Platinum & $47(86 \%)$ & $20(83 \%)$ & $27(87 \%)$ & 0.718 \\
\hline Taxane & $52(94 \%)$ & $23(96 \%)$ & 29 (94\%) & 1 \\
\hline Ramucirumab & $46(84 \%)$ & $20(83 \%)$ & $26(84 \%)$ & 0.471 \\
\hline Trastuzumab & $11(20 \%)$ & $1(4 \%)$ & $10(32 \%)$ & 0.015 \\
\hline Irinotecan & $14(26 \%)$ & $5(21 \%)$ & $9(29 \%)$ & 0.547 \\
\hline $\begin{array}{l}\text { Treatment period before nivolumab } \\
\text { (months) }\end{array}$ & $14.9(4.9-64.6)$ & $14.5(5.8-64.6)$ & $15.0(4.9-45.8)$ & 0.819 \\
\hline \multicolumn{5}{|l|}{ Best overall response } \\
\hline Responder & $18(33 \%)$ & $12(50 \%)$ & $6(19 \%)$ & \multirow[t]{2}{*}{0.022} \\
\hline Non-responder & $37(67 \%))$ & $12(50 \%)$ & $25(81 \%)$ & \\
\hline \multicolumn{5}{|c|}{ Immune-related adverse events ( $\geq$ grade 2 ) } \\
\hline Positive & $18(33 \%)$ & $9(38 \%)$ & $9(29 \%)$ & 0.57 \\
\hline
\end{tabular}

the number of patients with gastric cancer who benefit from nivolumab is limited, and it is necessary to identify biomarkers that can predict the outcome of treatment with this agent. Several studies have identified prognostic biomarkers of the effect of nivolumab monotherapy [9, 16-24]. However, several reports suggest that patients 


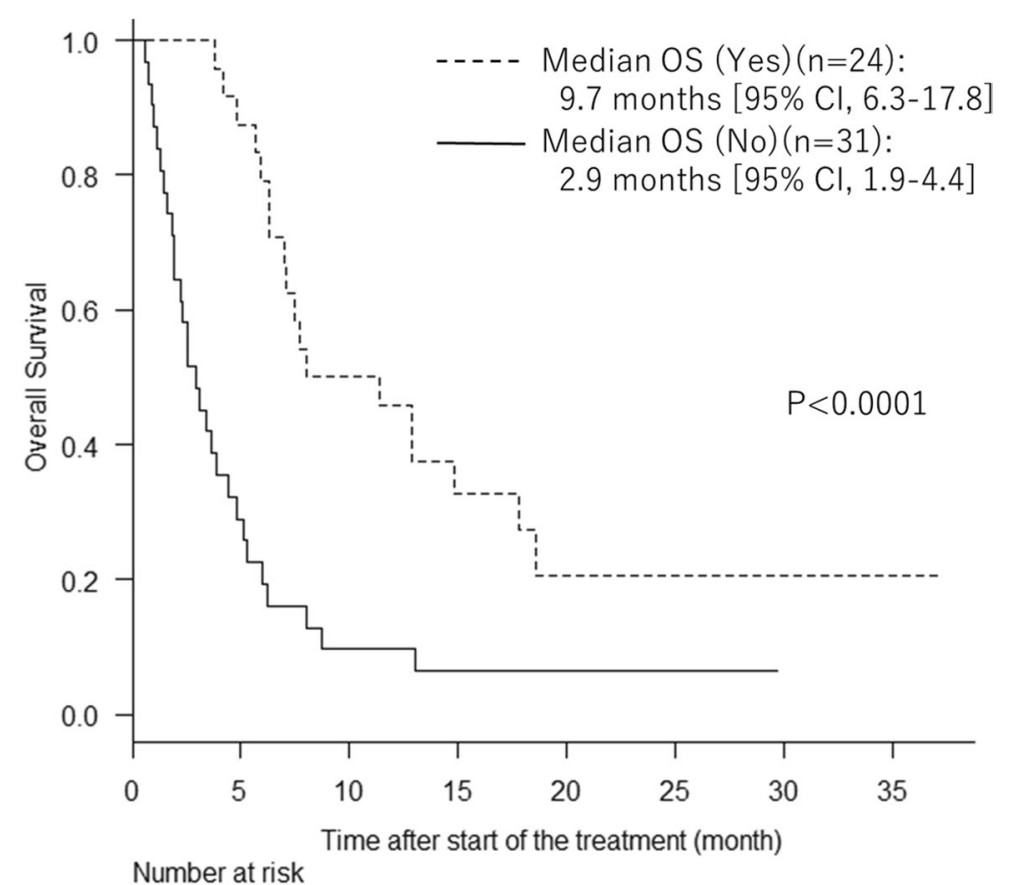

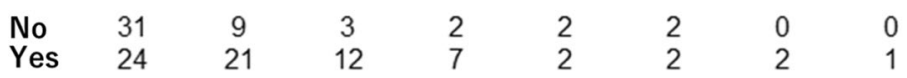

Fig. 2 Patients who were able to receive therapy subsequent to nivolumab showed significantly better overall survival than those who were not $(p<0.0001)$

with AGC and poor PS derive limited survival benefit from nivolumab $[9,17,18]$. As shown in several studies of pembrolizumab in patients who had previously been treated for AGC [25, 26], better ECOG PS was associated with a higher response rate and longer OS in those who were treated with an immune checkpoint inhibitor (ICI). Considering that nivolumab is an ICI that exerts an antitumor effect by activating tumor immunity, it is probable that the efficacy of nivolumab would be limited in patients with poor PS because of decreased immunity. For the same reason, the Glasgow prognostic score, neutrophil-lymphocyte ratio, prognostic nutrition index score, and skeletal muscle loss have been reported to affect the outcomes of treatment with nivolumab in patients with AGC $[16,19,23]$. The presence of a systemic inflammatory response and the associated poor nutritional status, indicating a low prognostic nutrition index score and high neutrophil-lymphocyte ratio, might adversely affect compliance with nivolumab for advanced gastric cancer [19]. Furthermore, patients with better ECOG PS at the start of nivolumab had a significantly higher rate of transition to subsequent chemotherapy after nivolumab, and this subsequent chemotherapy significantly contributed to OS improvement. Arigami et al. [27] report that nivolumab exposure may enhance subsequent chemosensitivity in patients with AGC, and our findings may support it.

In this study, 10 patients (17\%) experienced grade 2 or higher irAEs, and OS in these patients was significantly higher than that in those without irAEs. Development of irAEs is reportedly associated with better survival outcomes in various types of cancer, including AGC $[19,24$, 28-30]. By inhibiting PD-1 on T-cells, nivolumab reactivates suppressed T-cells and has antitumor effects. Given that irAEs are manifestations of the immune response through T-cell activation, they are likely to be related to the antitumor effect of nivolumab. Furthermore, T-cells enhance the effect of treatment with the PD-1 antibody, which may in turn induce autoantibodies via B-cells, thereby promoting the development of irAEs [21, 29]. Therefore, manifestation of irAEs might be a useful predictor of the response to nivolumab in patients with AGC.

Previous treatment with trastuzumab was associated with poor OS in patients with AGC who were treated with nivolumab, which is in contrast with the findings of the ATTRACTION-2 study [31]. Although the relationship between prior trastuzumab use and the therapeutic effect of nivolumab has not been clarified, the following mechanism has been implicated. 
Table 7 Overall and progression-free survival of patients treated by nivolumab using cox proportional hazard regression model

\begin{tabular}{|c|c|c|c|c|c|c|}
\hline \multirow[t]{2}{*}{ Variable } & \multicolumn{3}{|c|}{ Overall survival } & \multicolumn{3}{|c|}{ Progression-free survival } \\
\hline & HR & 95\% C.I. & $p$ value & HR & 95\% C.I. & $p$ value \\
\hline \multicolumn{7}{|l|}{ Sex } \\
\hline male & 1 & & & 1 & & \\
\hline female & 1.196 & $0.608-2.353$ & 0.604 & 1.714 & $0.913-3.220$ & 0.094 \\
\hline \multicolumn{7}{|l|}{ Age } \\
\hline$\leq 66$ & 1 & & & 1 & & \\
\hline$>66$ & 1.005 & $0.565-1.786$ & 0.987 & 0.8503 & $0.492-1.470$ & 0.561 \\
\hline \multicolumn{7}{|l|}{ ECOG PS } \\
\hline 0 & 1 & & & 1 & & \\
\hline$\geq 1$ & 3.472 & $1.236-9.753$ & 0.018 & 1.49 & $0.698-3.182$ & 0.303 \\
\hline \multicolumn{7}{|l|}{ Primary site } \\
\hline Gastric & 1 & & & 1 & & \\
\hline Esophagogastric junction & 0.8768 & $0.392-1.963$ & 0.749 & 0.669 & $0.301-1.487$ & 0.324 \\
\hline \multicolumn{7}{|l|}{ Disease status } \\
\hline Metastatic & 1 & & & 1 & & \\
\hline Relapsed & 1.241 & $0.321-4.798$ & 0.755 & 0.903 & 0.4899.-1.665 & 0.744 \\
\hline \multicolumn{7}{|l|}{ Histological type } \\
\hline Intestinal type & 1 & & & 1 & & \\
\hline Diffuse type & 0.881 & $0.490-1.581$ & 0.67 & 1.067 & $0.622-1.833$ & 0.813 \\
\hline \multicolumn{7}{|l|}{ Organ with metastasis } \\
\hline 1 & 1 & & & 1 & & \\
\hline$\geq 2$ & 1.656 & $0.858-3.196$ & 0.133 & 1.699 & $0.932-3.097$ & 0.084 \\
\hline \multicolumn{7}{|l|}{ Lymph node metastasis } \\
\hline no & 1 & & & 1 & & \\
\hline yes & 0.995 & $0.529-1.871$ & 0.987 & 0.959 & $0.539-1.707$ & 0.888 \\
\hline \multicolumn{7}{|l|}{ Hematogenous metastasis } \\
\hline no & 1 & & & 1 & & \\
\hline yes & 1.576 & $0.871-2.853$ & 0.133 & 1.491 & $0.860-2.584$ & 0.155 \\
\hline \multicolumn{7}{|l|}{ Peritoneal metastasis } \\
\hline no & 1 & & & 1 & & \\
\hline yes & 1.049 & $0.591-1.862$ & 0.8701 & 0.969 & $0.566-1.659$ & 0.909 \\
\hline \multicolumn{7}{|l|}{ Previous treatment regimens } \\
\hline 2 & 1 & & & 1 & & \\
\hline$\geq 3$ & 1.325 & $0.742-2.367$ & 0.342 & 1.103 & $0.636-1.911$ & 0.728 \\
\hline \multicolumn{7}{|l|}{ HER-2 status } \\
\hline no & 1 & & & 1 & & \\
\hline yes & 1.923 & $0.985-3.754$ & 0.055 & 1.7 & $0.886-3.262$ & 0.111 \\
\hline \multicolumn{7}{|l|}{ Prior trastuzumab } \\
\hline no & 1 & & & 1 & & \\
\hline yes & 2.123 & $1.036-4.352$ & 0.040 & 1.672 & $0.844-3.313$ & 0.141 \\
\hline \multicolumn{7}{|l|}{ Prior ramucirumab } \\
\hline no & 1 & & & 1 & & \\
\hline yes & 1.082 & $0.504-2.319$ & 0.841 & 1.265 & $0.616-2.596$ & 0.522 \\
\hline \multicolumn{7}{|c|}{ Treatment period before nivolumab } \\
\hline$\leq 14.9$ & 1 & & & 1 & & \\
\hline$>14.9$ & 0.924 & $0.521-1.639$ & 0.787 & 0.889 & $0.520-1.519$ & 0.666 \\
\hline \multicolumn{7}{|c|}{ Immune-related adverse events ( $\geq$ grade 2 ) } \\
\hline no & 1 & & & 1 & & \\
\hline yes & 0.3174 & $0.124-0.815$ & 0.017 & 0.615 & $0.298-1.271$ & 0.19 \\
\hline
\end{tabular}


Table 7 (continued)

\begin{tabular}{|c|c|c|c|c|c|c|}
\hline \multirow[t]{2}{*}{ Variable } & \multicolumn{3}{|c|}{ Overall survival } & \multicolumn{3}{|c|}{ Progression-free survival } \\
\hline & HR & 95\% C.I. & $p$ value & HR & 95\% C.I. & $p$ value \\
\hline \multicolumn{7}{|c|}{ Best overall response } \\
\hline Non-responder & 1 & & & 1 & & \\
\hline Responder & 0.14 & $0.065-0.302$ & $<0.001$ & 0.036 & $0.011-0.113$ & $<0.001$ \\
\hline \multicolumn{7}{|c|}{ Subsequent chemotherapy after nivolumab } \\
\hline No & 1 & & & 1 & & \\
\hline Yes & 0.31 & $0.169-0.567$ & $<0.001$ & 0.596 & $0.346-1.025$ & 0.061 \\
\hline
\end{tabular}

Trastuzumab has been reported to induce rapid increases in localization of phosphatase and tensin homolog (PTEN) to the membrane and phosphatase activity by reducing PTEN tyrosine phosphorylation via Src inhibition [32]. That is, trastuzumab has an antitumor effect via activation of PTEN, and loss of PTEN is predicted to be involved in resistance to trastuzumab. Furthermore, previous studies have shown that loss of PTEN contributes to resistance to T-cell-mediated immunotherapy $[33,34]$. From the perspective of loss of PTEN, nivolumab may be less effective in patients with AGC who are resistant to trastuzumab, and further molecular biological studies may be needed.

Until now, nivolumab has been limited to third line treatment in the indications of gastric cancer and esophagogastric junction cancer after failure of two or more alternative treatment regimens, but it is expected to be effective in the first line, second line, and adjuvant therapy in the future [35-38]. In the results of the randomized open-label Phase III CheckMate 649 study, the efficacy of nivolumab as first-line treatment in combination with chemotherapy have been reported [35]. In the CheckMate 577 study, it has been reported that disease-free survival was significantly longer in patients with resected esophageal or gastroesophageal junction cancer who received nivolumab as adjuvant therapy after neoadjuvant chemoradiotherapy than in those who received placebo as adjuvant therapy [38].

This study has some limitations. First, it had a single-arm, retrospective, non-randomized observational design and included a relatively small number of patients. Therefore, although the study was conducted at multiple centers, the possibility of selection bias cannot be excluded. Second, a multivariate analysis could not be conducted because of the relatively small cohort size. Third, poor prognostic factors were identified based on clinical data with no molecular biological analysis, especially regarding the correlation between prior trastuzumab use and nivolumab refractory. Further studies are required in the future.

\section{Conclusions}

In conclusion, this multicenter retrospective study identified that an ECOG PS of 0, no prior treatment with trastuzumab, presence of irAEs, response to nivolumab, and ability to administer chemotherapy subsequent to nivolumab were potential prognostic markers of prolonged OS after initiation of nivolumab in patients with AGC. Our study findings suggest that nivolumab should not recommended in patients with AGC who have poor PS and those who have previously been treated with trastuzumab. Further molecular biological studies are needed, in particular to identify the mechanism of intolerance to nivolumab in patients with AGC that is resistant to trastuzumab.

\begin{abstract}
Abbreviations
AGC: Advanced or recurrent gastric cancer; HER2: Human epidermal growth factor receptor 2; PD-1: Programmed cell death-1; OS: Overall survival; HR: Hazard ratio; ECOG PS: Eastern cooperative oncology group performance status; CR: Complete remission; PR: Partial response; SD: Stable disease; PD: Progressive disease; RECIST: Response evaluation criteria in solid tumors; AEs: Adverse events; irAEs: Immune-related adverse events; PFS: Progression-free survival; Cls: Confidence intervals; DCR: Disease control rate; TRAEs: Treatmentrelated adverse events; ICI: Immune checkpoint inhibitor; PTEN: Phosphatase and tensin homolog
\end{abstract}

Acknowledgements

We would like to thank Editage (www.editage.com) for English language editing.

\section{Authors' contributions}

$\mathrm{AS}, \mathrm{AK}, \mathrm{NK}$, and $\mathrm{KO}$ were involved in the conceptualization. AS, MSo, KSh, and $\mathrm{HS}$ edited the manuscript. AS, NN, YU, KK, HH, AN, MS, KSa, MSa, and $\mathrm{HO}$ collected the patients' data. AS, MSo, and HS analyzed the patients' data. All of the Authors have read and approved the manuscript.

\section{Funding}

The authors declare no funding support for this study.

\section{Availability of data and materials}

The datasets generated during and/or analyzed during the current study are available from the corresponding author on reasonable request.

\section{Declarations}

\section{Ethics approval and consent to participate}

Our study was carried out according to the relevant guidelines and regulations of the institutional and/or national research committee and the 1964 Helsinki declaration. The study protocol was approved by the Institutional 
Review Board (IRB) of Gunma University Hospital (approval number HS2018-237), Gunma Prefectural Cancer Center, National Hospital Organization Takasaki General Medical Center, Isesaki Municipal Hospital, and Japan Community Healthcare Organization Gunma Central Hospital. Because this study was strictly retrospective and involving the collection of existing data and records, the requirement to obtain informed consent was waived by the IRB of the Gunma University Hospital. And the opt-out method was used to obtain participant's consent.

\section{Consent for publication}

Not applicable.

\section{Competing interests}

The authors declare that they have no competing interests.

\section{Author details}

${ }^{1}$ Department of General Surgical Science, Gunma University Graduate School of Medicine, 3-39-22 Showa-machi, Maebashi, Gunma 371-8511, Japan. ${ }^{2}$ Department of Gastroenterology, Gunma Prefectural Cancer Center, 617-1 Takabayashi nishi-machi, Ohta, Gunma 373-8550, Japan. ${ }^{3}$ Department of Gastroenterology, National Hospital Organization Takasaki General Medical Center, 36 Takamatsu-machi, Takasaki, Gunma 370-0829, Japan. ${ }^{4}$ Department of Gastroenterology, Isesaki Municipal Hospital, 12-1 Tsunatori hon-machi, Isesaki, Gunma 372-0817, Japan. ${ }^{5}$ Department of Surgery, Japan Community Healthcare Organization Gunma Central Hospital, 1-7-13 Kouuncho, Maebashi, Gunma 371-0025, Japan.

Received: 10 October 2021 Accepted: 15 December 2021 Published online: 03 January 2022

\section{References}

1. Japanese Gastric Cancer Association. Japanese gastric cancer treatment guidelines. Gastric Cancer. 2018:24:1-21 5th ed.

2. Boku N, Yamamoto S, Fukuda H, Shirao K, Doi T, Sawaki A, et al. Fluorouracil versus combination of irinotecan plus cisplatin versus S-1 in metastatic gastric cancer: a randomised phase 3 study. Lancet Oncol. 2009;10:10639. https://doi.org/10.1016/S1470-2045(09)70259-1.

3. Koizumi W, Narahara H, Hara T, Takagane A, Akiya T, Takagi M, et al. S-1 plus cisplatin versus S-1 alone for first-line treatment of advanced gastric cancer (SPIRITS trial): a phase III trial. Lancet Oncol. 2008;9:215-21. https:// doi.org/10.1016/S1470-2045(08)70035-4.

4. Kang YK, Kang WK, Shin DB, Chen J, Xiong J, Wang J, et al. Capecitabine/ cisplatin versus 5 -fluorouracil/cisplatin as first-line therapy in patients with advanced gastric cancer: a randomised phase III noninferiority trial. Ann Oncol. 2009;20:666-73. https://doi.org/10.1093/annonc/mdn717.

5. Al-Batran SE, Hartmann JT, Probst S, Schmalenberg H, Hollerbach S, Hofheinz R, et al. Phase III trial in metastatic gastroesophageal adenocarcinoma with fluorouracil, leucovorin plus either oxaliplatin or cisplatin: a study of the Arbeitsgemeinschaft Internistische Onkologie. J Clin Oncol. 2008;26:1435-42. https://doi.org/10.1200/JCO.2007.13.9378.

6. Yamada Y, Higuchi K, Nishikawa K, Gotoh M, Fuse N, Sugimoto N, et al. Phase III study comparing oxaliplatin plus S-1 with cisplatin plus S-1 in chemotherapy-naive patients with advanced gastric cancer. Ann Oncol. 2015;26:141-8. https://doi.org/10.1093/annonc/mdu472.

7. Bang YJ, Van Cutsem E, Feyereislova A, Chung HC, Shen L, Sawaki A, et al. Trastuzumab in combination with chemotherapy versus chemotherapy alone for treatment of HER2-positive advanced gastric or gastrooesophageal junction cancer (ToGA): a phase 3, open-label, randomized controlled trial. Lancet. 2010;376:687-97. https://doi.org/10.1016/S01406736(10)61121-X.

8. Wilke H, Muro K, Van Cutsem E, Oh SC, Bodoky G, Shimada Y, et al. Ramucirumab plus paclitaxel versus placebo plus paclitaxel in patients with previously treated advanced gastric or gastro-oesophageal junction adenocarcinoma (RAINBOW): a double-blind, randomised phase 3 trial. Lancet Oncol. 2014;15:1224-35. https://doi.org/10.1016/S1470-2045(14) 70420-6.

9. Kang YK, Boku N, Satoh T, Ryu MH, Chao Y, Kato K, et al. Nivolumab in patients with advanced gastric or gastro-oesophageal junction cancer refractory to, or intolerant of, at least two previous chemotherapy regimens (ONO-4538-12, ATTRACTION-2): a randomised, double-blind, placebo-controlled, phase 3 trial. Lancet. 2017;390:2461-71. https://doi. org/10.1016/S0140-6736(17)31827-5.

10. Boku N, Satoh T, Ryu MH, Chao Y, Kato K, Chung HC, et al. Nivolumab in previously treated advanced gastric cancer (ATTRACTION-2): 3 -year update and outcome of treatment beyond progression with nivolumab. Gastric Cancer. 2021;24:946-58. https://doi.org/10.1007/ s10120-021-01173-w.

11. Eisenhauer EA, Therasse P, Bogaerts J, Schwartz LH, Sargent D, Ford R, et al. New response evaluation criteria in solid tumours: revised RECIST guideline (version 1.1). Eur J Cancer.1 version. 2009;45:228-47. https://doi. org/10.1016/j.ejca.2008.10.026.

12. Weber JS, D'Angelo SP, Minor D, Hodi FS, Gutzmer R, Neyns B, et al. Nivolumab versus chemotherapy in patients with advanced melanoma who progressed after anti-CTLA-4 treatment (CheckMate 037): a randomised, controlled, open-label, phase 3 trial. Lancet Oncol. 2015;16:37584. https://doi.org/10.1016/S1470-2045(15)70076-8.

13. Teraoka S, Fujimoto D, Morimoto T, Kawachi H, Ito M, Sato Y, et al. Early immune-related adverse events and association with outcome in advanced non-small cell lung cancer patients treated with nivolumab: a prospective cohort study. J Thorac Oncol. 2017;12:1798-805. https://doi. org/10.1016/j.jtho.2017.08.022.

14. Robert C, Long GV, Brady B, Dutriaux C, Maio M, Mortier L, et al. Nivolumab in previously untreated melanoma without BRAF mutation. $N$ Engl J Med. 2015;372:320-30. https://doi.org/10.1056/NEJMoa1412082.

15. Kanda Y. Investigation of the freely available easy-to-use software "EZR" for medical statistics. Bone Marrow Transplant. 2013;48:452-8. https://doi. org/10.1038/bmt.2012.244.

16. Tokuyama N, Takegawa N, Nishikawa M, Sakai A, Mimura T, Kushida S, et al. Pretreatment Glasgow prognostic score as a predictor of outcomes in nivolumab-treated patients with advanced gastric cancer. PLoS One. 2021;16:e0247645. https://doi.org/10.1371/journal.pone.0247645.

17. Matsumoto T, Yamamoto Y, Kuriona Y, Okazaki U, Kimura S, Miura K, et al. Efficacy and safety of nivolumab for advanced gastric cancer patients with poor performance statuses. BMC Cancer. 2020;20:684. https://doi. org/10.1186/s12885-020-07176-7.

18. Hagi T, Kurokawa Y, Kawabata R, Omori T, Matsuyama J, Fujitani K, et al. Multicentre biomarker cohort study on the efficacy of nivolumab treatment for gastric cancer. Br J Cancer. 2020;123:965-72. https://doi.org/10. 1038/s41416-020-0975-7.

19. Namikawa T, Yokota K, Tanioka N, Fukudome I, Iwabu J, Munekage $\mathrm{M}$, et al. Systemic inflammatory response and nutritional biomarkers as predictors of nivolumab efficacy for gastric cancer. Surg Today. 2020;50:1486-95. https://doi.org/10.1007/s00595-020-02048-w.

20. Petrillo A, Tirino G, Zito Marino F, Pompella L, Sabetta R, Panarese I, et al. Nivolumab in heavily pretreated metastatic gastric Cancer patients: reallife data from a Western population. Onco Targets Ther. 2020;13:867-76. https://doi.org/10.2147/OTT.S229813.

21. Mishima S, Kawazoe A, Nakamura Y, Sasaki A, Kotani D, Kuboki Y, et al. Clinicopathological and molecular features of responders to nivolumab for patients with advanced gastric cancer. J Immunother Cancer. 2019;7:24. https://doi.org/10.1186/s40425-019-0514-3.

22. Ogata T, Satake H, Ogata M, Hatachi Y, Inoue K, Hamada M, et al. Neutrophil-to-lymphocyte ratio as a predictive or prognostic factor for gastric cancer treated with nivolumab: a multicenter retrospective study. Oncotarget. 2018;9:34520-7. https://doi.org/10.18632/oncotarget.26145.

23. Kano M, Hihara J, Tokumoto N, Kohashi T, Hara T, Shimbara K, et al. Association between skeletal muscle loss and the response to nivolumab immunotherapy in advanced gastric cancer patients. Int J Clin Oncol. 2021;26:523-31. https://doi.org/10.1007/s10147-020-01833-4.

24. Masuda K, Shoji H, Nagashima K, Yamamoto S, Ishikawa M, Imazeki $H_{\text {, }}$ et al. Correlation between immune-related adverse events and prognosis in patients with gastric cancer treated with nivolumab. BMC Cancer. 2019;19:974. https://doi.org/10.1186/s12885-019-6150-y.

25. Fuchs CS, Doi T, Jang RW, Muro K, Satoh T, Machado M, et al. Safety and efficacy of pembrolizumab monotherapy in patients with previously treated advanced gastric and gastroesophageal junction cancer: phase 2 clinical KEYNOTE-059 trial. JAMA Oncol. 2018;4:e180013. https://doi.org/ 10.1001/jamaoncol.2018.0013.

26. Shitara K, Özgüroğlu M, Bang YJ, Di Bartolomeo M, Mandalà M, Ryu MH, et al. Pembrolizumab versus paclitaxel for previously treated, advanced 
gastric or gastrooesophageal junction cancer (KEYNOTE-061): a randomised, open-label, controlled, phase 3 trial. Lancet. 2018;392:123-33. https://doi.org/10.1016/S0140-6736(18)31257-1.

27. Arigami T, Matsushita D, Okubo K, Yanagita S, Ehi K, Sasaki K, et al. Response rate and prognostic impact of salvage chemotherapy after Nivolumab in patients with advanced gastric Cancer. Oncology. 2020;98(9):630-6. https://doi.org/10.1159/000507219.

28. Haratani K, Hayashi H, Chiba Y, Kudo K, Yonesaka K, Kato R, et al. Association of immune-related adverse events with nivolumab efficacy in non-small-cell lung cancer. JAMA Oncol. 2018;4:374-8. https://doi.org/10 1001/jamaoncol.2017.2925.

29. Toi Y, Sugawara S, Kawashima Y, Aiba T, Kawana S, Saito R, et al. Association of immune-related adverse events with clinical benefit in patients with advanced non-small-cell lung cancer treated with nivolumab. Oncologist. 2018;23:1358-65. https://doi.org/10.1634/theoncologist. 2017-0384.

30. Ricciuti B, Genova C, De Giglio A, Bassanelli M, Dal Bello MG, Metro G, et al. Impact of immune-related adverse events on survival in patients with advanced non-small cell lung cancer treated with nivolumab: long-term outcomes from a multi-institutional analysis. J Cancer Res Clin Oncol. 2019;145:479-85. https://doi.org/10.1007/s00432-018-2805-3.

31. Satoh T, Kang YK, Chao Y, Ryu MH, Kato K, Cheol Chung H, et al. Exploratory subgroup analysis of patients with prior trastuzumab use in the ATT RACTION-2 trial: a randomized phase III clinical trial investigating the efficacy and safety of nivolumab in patients with advanced gastric/gastroesophageal junction cancer. Gastric Cancer. 2020;23:143-53. https:// doi.org/10.1007/s10120-019-00970-8.

32. Nagata Y, Lan KH, Zhou X, Tan M, Esteva FJ, Sahin AA, et al. PTEN activation contributes to tumor inhibition by trastuzumab, and loss of PTEN predicts trastuzumab resistance in patients. Cancer Cell. 2004;6:117-27. https:// doi.org/10.1016/j.ccr.2004.06.022.

33. Peng W, Chen JQ, Liu C, Malu S, Creasy C, Tetzlaff MT, et al. Loss of PTEN promotes resistance to $T$ cell-mediated immunotherapy. Cancer Discov. 2016;6:202-16. https://doi.org/10.1158/2159-8290.CD-15-0283.

34. Waldron JS, Yang I, Han S, Tihan T, Sughrue ME, Mills SA, et al. Implications for immunotherapy of tumor-mediated T-cell apoptosis associated with loss of the tumor suppressor PTEN in glioblastoma. J Clin Neurosci. 2010;17:1543-7. https://doi.org/10.1016/j.jocn.2010.04.021.

35. Janjigian YY, Shitara K, Moehler M, Garrido M, Salman P, Shen L, et al. First-line nivolumab plus chemotherapy versus chemotherapy alone for advanced gastric, gastro-oesophageal junction, and oesophageal adenocarcinoma (CheckMate 649): a randomised, open-label, phase 3 trial. Lancet. 2021;398:27-40. https://doi.org/10.1016/S0140-6736(21)00797-2.

36. Kawakami H, Hironaka S, Esaki T, Chayama K, Tsuda M, Sugimoto N, et al. An investigator-initiated phase 2 study of nivolumab plus low-dose ipilimumab as first-line therapy for microsatellite instability-high advanced gastric or esophagogastric junction cancer (NO LIMIT, WJOG13320G/ CA209-7W7). Cancers (Basel). 2021;13:805. https://doi.org/10.3390/cance rs13040805.

37. Nakajima TE, Kadowaki S, Minashi K, Nishina T, Yamanaka T, Hayashi Y, et al. Multicenter phase I/II study of nivolumab combined with paclitaxel plus ramucirumab as second-line treatment in patients with advanced gastric cancer. Clin Cancer Res. 2021;27:1029-36. https://doi.org/10.1158/ 1078-0432.CCR-20-3559.

38. Kelly RJ, Ajani JA, Kuzdzal J, Zander T, Van Cutsem E, Piessen G, et al. Adjuvant nivolumab in resected esophageal or gastroesophageal junction cancer. N Engl J Med. 2021;384:1191-203. https://doi.org/10.1056/NEJMo a2032125.

\section{Publisher's Note}

Springer Nature remains neutral with regard to jurisdictional claims in published maps and institutional affiliations.

Ready to submit your research? Choose BMC and benefit from:

- fast, convenient online submission

- thorough peer review by experienced researchers in your field

- rapid publication on acceptance

- support for research data, including large and complex data types

- gold Open Access which fosters wider collaboration and increased citations

- maximum visibility for your research: over $100 \mathrm{M}$ website views per year

At BMC, research is always in progress.

Learn more biomedcentral.com/submissions 